\title{
Early pulmonary response to allergen is attenuated during acute emotional stress in females with asthma
}

\author{
B.L. Laube*,\#, B.A. Curbow ${ }^{\#, \oplus}$, S.T. Fitzgerald" ${ }^{\#}$ K. Spratt ${ }^{\natural}$
}

Early pulmonary response to allergen is attenuated during acute emotional stress in females with asthma. B.L. Laube, B.A. Curbow, S.T. Fitzgerald, K. Spratt. (C)ERS Journals Ltd 2003.

ABSTRACT: Some asthma patients and physicians who treat asthma have reported that stress worsens their disease. It has also recently been shown that chronic stressful life events increase airway inflammation 6-24 h after inhalation of antigen in patients with allergic asthma. However, there is no data regarding the effect of an acute stressor on the airway constriction that occurs within minutes of antigen inhalation (early pulmonary response) in this same population. The aim of this study was to examine this effect in eight females with allergic asthma.

Each subject was challenged with increasing concentrations of inhaled allergen on a control visit (no stress) and on a stress visit, when they were asked to verbally recount an emotionally stressful situation between each concentration. Systolic (SP) and diastolic (DP) blood pressure, cardiac frequency $(f \mathrm{C})$ and forced expiratory volume in one second (FEV1) were measured on both visits.

SP, DP and $f C$ were statistically increased on the stress visit as compared to control. Per cent decrease in FEV1 at the same last dose of allergen was significantly less on the stress visit $(11.2 \pm 7.0 \%)$ compared to control $(15.0 \pm 8.7 \%)$.

These findings suggest that the early pulmonary response to inhaled allergen is attenuated while verbally re-experiencing an acute emotional stressor in females with allergic asthma.

Eur Respir J 2003; 22: 613-618.
*Dept of Pediatrics, School of Medicine, and ${ }^{\#}$ Dept of Environmental Health Sciences and "Dept of Health Policy and Management, Bloomberg School of Public Health, Johns Hopkins University, Baltimore, MD, USA.

Correspondence: B.L. Laube, Johns Hopkins Hospital, Park 316, 600 North Wolfe Street, Baltimore, MD 21287-2533, USA.

Fax: 014109551030

E-mail: blaube@jhmi.edu

\section{Keywords: Allergen challenge}

emotional stress

females with asthma

pulmonary function

Received: April 292002

Accepted after revision: May 52003

This research was supported in part by a Johns Hopkins University Faculty Development Award and by the Fetzer Institute (Kalamazoo, MI, USA).
Asthma is defined as reversible airway disease, characterised by airway inflammation, recurrent episodes of airway obstruction and increased airway responsiveness to a variety of stimuli. Stress is defined as a process in which environmental demands tax or exceed the adaptive capacity of an organism, resulting in psychological and biological changes that may place persons at risk for disease [1].

According to some asthma patients and some physicians who treat asthma, stress worsens the disease [2-4]. Results from several research studies support this notion. Subjects exposed to acute stressors, such as completing frustrating computer tasks [5], viewing highly emotional films [6] and verbally recording stressful events [7], showed increases in breathlessness [5], oscillatory resistance [6] and airway resistance [7].

In allergic asthma, acute airway constriction is triggered through an immunological mechanism involving an antigenantibody interaction. Exposure to specific environmental antigens within the lungs leads to the production of an antigen-specific antibody (immunoglobulin E) and the degranulation of mast cells through the activation of antibody attached to the cell membrane. During degranulation, bronchoconstricting mediators, such as histamine, prostaglandins and leukotrienes, are secreted. These stimulate smooth muscle receptors and cause airway constriction within minutes of antigen inhalation (early pulmonary response). It is thought that other mediators, released as a result of degranulation,

$\overline{\text { For editorial comments see page } 574 .}$ initiate a cascade of events that leads to airway inflammation and late phase responses.

Recently, LIU et al. [8] showed that chronic stressful life events increase airway inflammation 6-24 h after inhalation of antigen in patients with allergic asthma. However, there are no data regarding the effect of acute stress on the early pulmonary response in this same population. Based on previous reports, the current authors hypothesised that the early pulmonary response to allergen exposure would be potentiated in individuals who were subjected to an acute stressor, such as re-experiencing an emotionally stressful situation.

\section{Materials and methods}

\section{Study population}

Eight females $\geqslant 18$ yrs old, with a history of allergyinduced asthma were enrolled. Females alone were chosen because males and females vary in terms of the types of stimuli that they respond to as stressors in terms of life events [9] and experimental challenges [10]. They also have different psychosocial [9] and physiological [10] responses to the same stressors and it is believed that the integrity of their stress responses is not associated with the same personality variables [11-12]. In addition, in the $>20$ yrs-of-age category, females appear to be at greater risk from asthma, since they report 
greater asthma incidence and more hospitalisations than asthmatic males in the same age group [13-14].

\section{Study design}

This was a pilot study consisting of a screening visit and two study visits.

\section{Medications}

Prior to all study visits, inhaled bronchodilators were discontinued for $24 \mathrm{~h}$ and oral bronchodilators were discontinued for $48 \mathrm{~h}$. Inhaled corticosteroids were not discontinued.

\section{Inclusion criteria}

Inclusion criteria included: baseline forced expiratory volume in one second (FEV1) $>70 \%$ of predicted; normal systolic (SP) and diastolic blood pressures (DP); a normal cardiac frequency $\left(f_{C}\right) ; 2+$ intra-dermal skin test responses to increasing concentrations of ragweed extract (Greer Labortaories, Lenoir, NC, USA), cat extract (ALK Laboratories, Milford, CT, USA) or dust mite extract (Miles, Inc., Elkart, IN, USA); and completion of a recent life stress questionnaire.

\section{Exclusion criteria}

Exclusion criteria included: treatment with long-acting bronchodilators or oral steroids; hospitalisation for asthma within the last 3 months; a lower respiratory infection within the last 3 months; human immunodeficiency virus positive; and a history of drug or alcohol abuse.

\section{Study approval and informed consent}

This research was approved by the Committee for Human Research at the Johns Hopkins Bloomberg School of Public Health (Baltimore, MD, USA). All patients gave informed, signed consent.

\section{Screening visit}

Baseline FEV1 was quantified in an Auto Box 2800 body plethysmograph (Sensormedics, Inc., Anaheim, CA, USA).
Baseline SP, DP and $f$ C were quantified with a Dinamap 8100 automated blood pressure monitor (Johnson \& Johnson, Inc., Tampa, FL, USA) while patients sat quietly. Skin tests were performed as described by CHAI et al. [15]. Patients completed a Recent Life Stress questionnaire that was developed by the current authors. This questionnaire was constructed to assess levels of perceived chronic stress across 10 major life domains during the past 2 weeks. The domains included: relationships with spouse, children, family members, friends, neighbours, employer and co-workers; finances; job; and overall life. An emphasis was placed on relationships, as the literature suggests the importance of this type of stressor to females $[9,16]$. Patients rated stress in each area on a scale of $1-8$, with 8 as the highest score. Scores for all 10 areas were summed and normalised by dividing by 80 .

The Recent Life Stress questionnaire was previously validated by the authors in a group of 13 females who had a history of allergic asthma and were similar in age to the females who participated in the current study. Each female filled out two questionnaires concerning their level of chronic stress: the Recent Life Stress questionnaire and the LISRESA questionnaire developed by Moos [17].

Pearson correlations between the Recent Life Stress questionnaire and the LISRES-A instrument indicated that the Recent Life Stress questionnaire and the LISRES-A questionnaire were correlated at $\mathrm{p}<0.05, \mathrm{r}=0.66$ for stressors. This result showed good construct quality for the instrument used and indicated that it could be used to quickly determine a patient's level of recent chronic stress. The Recent Life Stress questionnaire required $\sim 5 \mathrm{~min}$ to complete.

\section{Stress visit}

The order of the two study visits was randomised. Procedures associated with the stress visit are summarised in figure 1. Baseline FEV1 was quantified in the body plethysmograph. Patients inhaled five breaths of aerosol generated from normal saline solution (Greer Laboratories) (control aerosol). Aerosol was generated by a \#646 nebuliser (DeVilbiss, Somerset, PA, USA) connected to a compressed air source set at 20 psi. Each aerosol pulse lasted $0.6 \mathrm{~s}$. Each inhalation started at $50 \%$ of vital capacity. Inspiratory flow during the inhalation procedure was regulated at $\sim 30 \mathrm{~L} \cdot \mathrm{min}^{-1}[18]$.

After inhalation, patients entered a small room and sat quietly for $11 \mathrm{~min}$ while SP, DP and $f \mathrm{C}$ were measured every 2 min with the automated blood pressure monitor. Afterwards, FEV1 was re-measured (control value). If there was no significant decrease in the FEV1 from baseline, patients

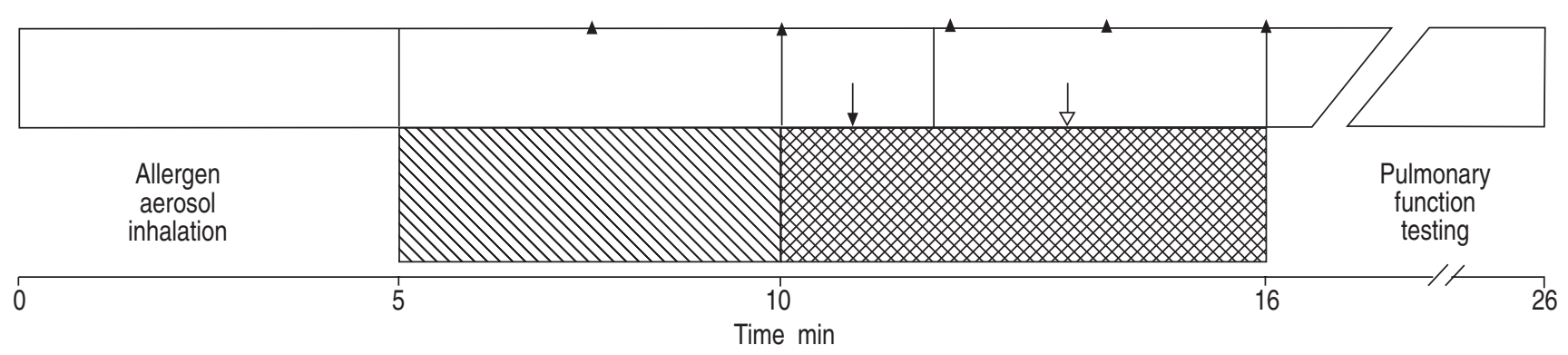

Fig. 1.-Schematic diagram of the procedures associated with the stress visit. After the first inhalation sequence, patients sat quietly for 11 min in a small room, while blood pressure (BP) and cardiac frequency $(f C)$ were measured every 2 min (arrow head). After their forced expiratory volume in one second (FEV1) was measured, they inhaled the first concentration of allergen and sat quietly in the room for 5 min ( $\mathbb{Q}$ ), while BP and $f \mathrm{C}$ were measured. They were then introduced to the interviewer. During the next 6 min, patients verbally described a personal, emotional situation to the interviewer (a) (arrow: description of the problem; open arrow: re-experiencing the problem), while BP and $f \mathrm{C}$ were measured every 2 min. Subsequently, their FEV1 was measured. Patients repeated this protocol with each concentration of allergen-extract until they either demonstrated $\mathrm{a} \geqslant 15 \%$ decrease in FEV1, or inhaled all of the concentrations of allergen that was available. 
inhaled five breaths of the first concentration of the allergen extract that produced the $2+$ skin test response on the screening visit. Aerosol was inhaled as described above. Subsequently, patients sat quietly in the room for $5 \mathrm{~min}$ while two measurements of SP, DP and $f$ C were obtained. Then, they were introduced to an interviewer (a member of the investigative team who was trained in behavioural psychology). During the next $2 \mathrm{~min}$, patients were asked to order a set of cards. Each card was labelled with a stressor that had appeared on the Recent Life Stress questionnaire. Each patient was asked to order the cards so that their worst stressor was first. Patients then talked to the interviewer about a personal, emotional situation associated with this first stressor for the next $4 \mathrm{~min}$. This stress interview was modelled on the social competence interview of EWART and KOLODNER [19]. SP, DP and $f C$ were automatically measured every 2 min, throughout the 6-min period that patients interacted with the interviewer.

At the end of the verbal disclosure, FEV1 was re-measured and expressed as per cent decrease from the control FEV1 value. If there was no significant decrease in the FEV1, subjects inhaled five breaths of the next higher concentration of allergen. They then either continued to verbally reexperience the stressful situation associated with the first stressor or began talking about another situation involving their next worst stressor. Six females talked about a situation that was associated with a different stressor after each inhalation exposure. Two females talked about the same situation for two or three exposures. Patients repeated this protocol until they either demonstrated $\geqslant 15 \%$ decrease in their FEV1 or inhaled all the allergen concentrations that were available. This challenge was modelled on that of $\mathrm{CHAI}$ et al. [15] for ragweed.

Ragweed extract concentrations included $0.08,0.16,0.32$, $0.64,1.28,2.56,5.12,10.24$ and $20.48 \mathrm{AgE}$ units $\cdot \mathrm{mL}^{-1}$. Dustmite extract concentrations included 10, 33.3, 100, 333.3, $1,000,3,333.3$ and $5,000 \mathrm{AU} \cdot \mathrm{mL}^{-1}$. Cat dander extract concentrations included 39, 78, 156, 312, 624, 1,248, 2,496 and $5,000 \mathrm{BAU} \cdot \mathrm{mL}^{-1}$.

\section{Control visit}

On the second visit, patients had to demonstrate a baseline FEV 1 that was $\pm 10 \%$ of the baseline FEV 1 recorded on the first study visit, or the visit was rescheduled. After obtaining baseline measurements, patients inhaled five breaths of the control aerosol, sat quietly in a small room for $11 \mathrm{~min}$ while control measurements of SP, DP and $f_{C}$ were obtained and underwent pulmonary function measurements. If there was no significant decrease in the FEV1 from baseline, patients inhaled five breaths of the same starting concentration of allergen extract as on the stress visit and sat quietly in the room for $11 \mathrm{~min}$ while measurements of SP, DP and $f \mathrm{C}$ were obtained. After $11 \mathrm{~min}$, FEV1 was re-measured and expressed as per cent decrease from the control FEV1 value. If there was no significant decrease in the FEV1, subjects inhaled five breaths of the next higher concentration of allergen, sat quietly in the small room for $11 \mathrm{~min}$ and underwent pulmonary function measurements. Patients repeated this protocol until they either demonstrated $\geqslant 15 \%$ decrease in their FEV1 or they inhaled all the allergen concentrations that were inhaled on the first study visit. In this way, patients underwent the same number of inhalation sequences on the stress and control visits and received the same cumulative load of allergen on both visits.

Time of day for the stress and control visits accommodated the patient's schedule and, therefore, varied between patients.
Nevertheless, visits for a given patient were always at the same time. To increase the likelihood that individual chronic stress levels would be similar on both visits, elapsed time between visits was short, ranging from a minimum of 4 days to a maximum of 21 days.

\section{Analysis}

Group data are presented as mean \pm SD. On both visits, the last three measurements for $\mathrm{SP}$, DP and $f \mathrm{C}$ after each inhalation sequence were averaged, since that was the time period during which patients retold their stressful experiences on the stress visit. For allergen inhalation sequences, means for each parameter were averaged and subtracted from the average value for the control inhalation sequence (no allergen) on that visit, yielding mean absolute change from control for the entire visit for each of the three parameters. Mean control measurements for SP, DP and $f$ C on the two visits, mean SP, DP and $f$ C for all allergen inhalation sequences combined on the two visits, mean absolute change in SP, DP and $f$ C on the two visits, and per cent decrease in FEV1 from control values at the same last dose of allergen on the two visits were compared by Wilcoxon signed-rank tests. A p-value of $<0.05$ indicated a statistically significant difference.

\section{Results}

\section{Study population}

The characteristics and protocol features associated with the study patients are shown in table 1 .

\section{Order of the visits}

Patients 3, 4, 5 and 8 were stress visit/control visit. Patients $1,2,6$ and 7 were control visit/stress visit.

\section{Effect of acute emotional stress on cardiovascular parameters}

Table 2 shows the mean of the last three control measurements for SP, DP and $f_{\mathrm{C}}$ for each patient on the two visits. Mean values were not significantly different for any parameter on the control visit as compared to the stress visit. These data also show that patients were not significantly more stressed at the start of their first visit compared to their second.

In contrast, mean SP, DP and $f_{\mathrm{C}}$ for all allergen inhalation sequences combined were elevated on the stress visit, with $134 \pm 15 \mathrm{mmHg}, 84 \pm 9 \mathrm{mmHg}$ and $75 \pm 8$ beat $\cdot \mathrm{min}^{-1}$, respectively, as compared to the control visit, with $115 \pm 13 \mathrm{mmHg}$, $73 \pm 8 \mathrm{mmHg}$ and $70 \pm 8$ beats $\cdot \mathrm{min}^{-1}$, respectively $(\mathrm{p}<0.05$ for SP and DP).

When normalised in terms of the control value (no allergen), mean absolute changes from control on the stress visit were 21.2 $\pm 7.1 \mathrm{mmHg}(\mathrm{SP}), 11.9 \pm 4.9 \mathrm{mmHg}(\mathrm{DP})$ and $5.6 \pm 1.5$ beat $\min ^{-1}(f \mathrm{C})$. These were statistically higher than the changes observed on the control visit with $3.1 \pm 6.0 \mathrm{mmHg}(\mathrm{SP}), 1.8 \pm$ $3.6 \mathrm{mmHg}(\mathrm{DP})$ and $-2.4 \pm 2.4$ beats $\cdot \mathrm{min}^{-1}(f \mathrm{C})$, and indicated a significant physiological response during verbal disclosure of the stressful situations (all $\mathrm{p}<0.05$ ) (fig. 2).

With the exception of patients 4 and 5, maximum increases in SP and DP occurred after the last or next-to-last inhalation 
Table 1. - Characteristics and protocol features associated with eight study patients

\begin{tabular}{|c|c|c|c|c|c|c|c|c|c|}
\hline \multirow{2}{*}{$\begin{array}{l}\text { Patient } \\
\text { no. }\end{array}$} & \multirow{2}{*}{$\begin{array}{l}\text { Age } \\
\text { yrs }\end{array}$} & \multirow[t]{2}{*}{ BMI } & \multirow[t]{2}{*}{ Race } & \multirow{2}{*}{$\begin{array}{l}\text { Recent Life } \\
\text { Stress score }\end{array}$} & \multirow{2}{*}{$\begin{array}{l}\text { Positive skin } \\
\text { test reaction }\end{array}$} & \multicolumn{2}{|c|}{ FEV1 \% pred } & \multirow{2}{*}{$\begin{array}{c}\text { Current } \\
\text { medications }\end{array}$} & \multirow{2}{*}{$\begin{array}{c}\text { Inhalation } \\
\text { sequences } \\
n\end{array}$} \\
\hline & & & & & & Control & Stress & & \\
\hline 1 & 30 & 28.34 & $\mathrm{CA}$ & 0.48 & Cat & 92 & 91 & $\mathrm{OB}, \mathrm{IB}$ & 5 \\
\hline 2 & 19 & 29.17 & AA & 0.24 & Ragweed & 102 & 96 & IB & 6 \\
\hline 3 & 35 & 26.61 & $\mathrm{CA}$ & 0.60 & Ragweed & 78 & 80 & IB & 3 \\
\hline 4 & 29 & 25.74 & $\mathrm{AA}$ & 0.48 & Cat & 98 & 97 & IB & 5 \\
\hline 5 & 43 & 25.79 & $\mathrm{CA}$ & $\begin{array}{l}0.40 \\
0.30\end{array}$ & Cat & 100 & 107 & IB & 5 \\
\hline 6 & 44 & 37.50 & $\mathrm{AA}$ & 0.29 & Ragweed & 92 & 93 & IB & 1 \\
\hline 7 & 37 & 21.29 & $\mathrm{CA}$ & 0.48 & Dust mite & 80 & 78 & IB, IC & 2 \\
\hline 8 & 40 & 20.79 & $\mathrm{CA}$ & 0.44 & Cat & 107 & 109 & IB, IC & 2 \\
\hline Mean \pm SD & $35 \pm 8$ & $26.90 \pm 5.22$ & & $0.41 \pm 0.12$ & & $93.6 \pm 10.3$ & $93.9 \pm 11.1$ & & \\
\hline
\end{tabular}

BMI: body mass index; FEV1: forced expiratory volume in one second; CA: Caucasian American; AA: African American; Cat: cat allergen; Ragweed: ragweed allergen; Dust mite: dust mite allergen; OB: oral bronchodilator; IB: inhaled bronchodilator; IC: inhaled corticosteroid.

Table 2. - Mean control measurements (no allergen) for systolic (SP) and diastolic (DP) blood pressure, and cardiac frequency $(f c)$

\begin{tabular}{|c|c|c|c|c|c|c|}
\hline \multirow[t]{2}{*}{ Patient no. } & \multicolumn{2}{|c|}{ SP } & \multicolumn{2}{|c|}{ DP } & \multicolumn{2}{|c|}{$f \mathrm{C}$} \\
\hline & Control mmHg & Stress $\mathrm{mmHg}$ & Control mmHg & Stress $\mathrm{mmHg}$ & Control beats $\cdot \min ^{-1}$ & Stress beat $\cdot \mathrm{min}^{-1}$ \\
\hline 1 & 108 & 105 & 83 & 81 & 72 & 73 \\
\hline 2 & 108 & 103 & 64 & 66 & 76 & 66 \\
\hline 3 & 95 & 96 & 63 & 72 & 74 & 71 \\
\hline 4 & 104 & 108 & 66 & 68 & 86 & 75 \\
\hline 5 & 116 & 118 & 68 & 72 & 65 & 62 \\
\hline 6 & 124 & 137 & 74 & 79 & 77 & 81 \\
\hline 7 & 110 & 114 & 70 & 74 & 55 & 60 \\
\hline 8 & 130 & 117 & 81 & 77 & & 60 \\
\hline Mean \pm SD & $112 \pm 11$ & $112 \pm 13$ & $71 \pm 8$ & $74 \pm 5$ & $72 \pm 10$ & $69 \pm 8$ \\
\hline
\end{tabular}

of allergen. With the exception of patients 1,4 and 5 , this was also true for increases in $f$ c. These data suggest that, in most of the patients, arousal was maintained throughout the inhalation sequences.

\section{Effect of acute emotional stress on the pulmonary response to allergen challenge}

Figure 3 shows that six patients demonstrated less of a fall in their FEV1 at the same last dose of allergen on the stress visit as compared to the control visit. Mean falls were

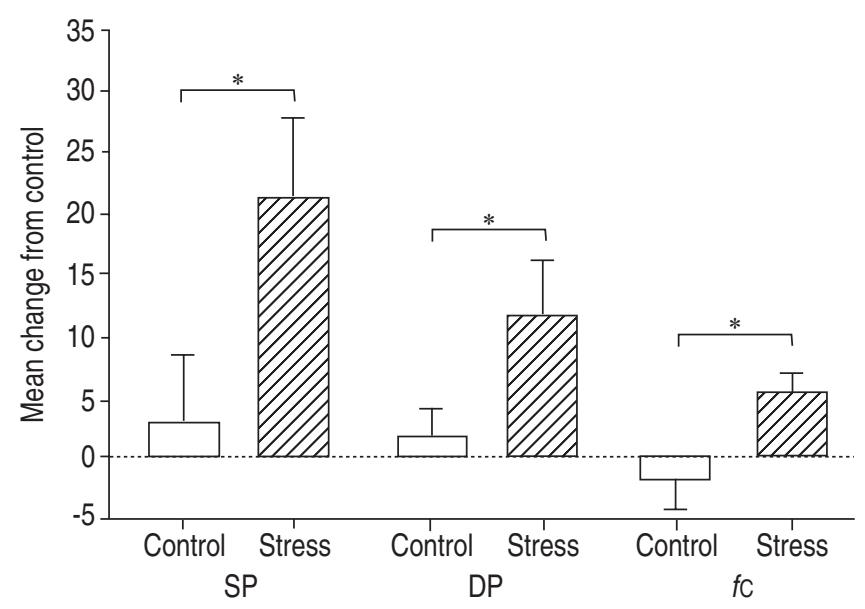

Fig. 2.-Mean absolute changes from control in systolic (SP) and diastolic (DP) blood pressure and cardiac frequency $(f \mathrm{C})$ on the control visit and stress visit. Compared to the control visit, mean SP, DP and $f \mathrm{C}$ were each significantly higher on the stress visit. *: $\mathrm{p}<0.05$. statistically different, $11.2 \pm 7.0 \%$ and $15.0 \pm 8.7 \%$, respectively $(\mathrm{p}<0.05)$, indicating attenuation in the FEV1 response on the stress visit compared to the control visit. Decreases in FEV1 were not large on either study visit.

\section{Discussion}

The current authors hypothesised that the early pulmonary response to allergen exposure in females with allergic asthma would be potentiated following the verbal re-experiencing of an acutely emotional situation (acute stressor). However, it was found that only one patient in the study demonstrated potentiation of the pulmonary response, while seven patients demonstrated attenuation (fig. 3).

The effect of the acute stressor on the early pulmonary response to inhaled allergen varied between patients. Three patients demonstrated $\mathrm{a}+6,+7$ and $+11 \%$ difference in their FEV1 between the two visits. Three patients demonstrated more modest differences of $+1,+2$ and $+3 \%$. One patient showed no difference. Interestingly, patient 3 had the highest Recent Life Stress score and was the only patient to show potentiation of the pulmonary response on the stress visit. In contrast, patients 2, 5 and 6 had the lowest scores on the Recent Life Stress questionnaire and also demonstrated the greatest attenuation of their pulmonary response on the stress visit. These data suggest that differences in the levels of chronic stress in the patients in the study may have affected the degree of attenuation of the pulmonary response to inhaled allergen.

Differences in the degree of attenuation in the present study could also be due to individual differences in the amount of adrenaline that was secreted by the adrenal medulla during activation of the sympathetic nervous system in response 


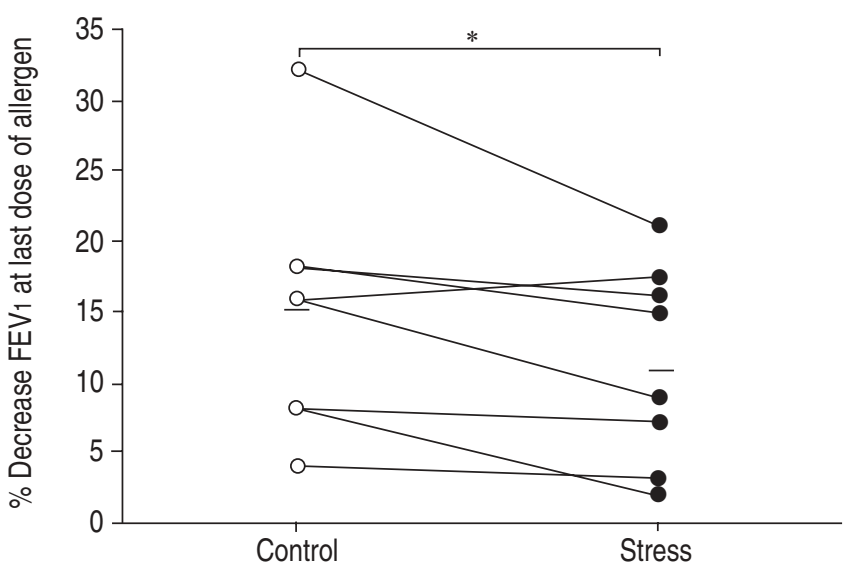

Fig. 3. - Per cent decrease in forced expiratory volume (FEV 1$)$ at the same last dose of inhaled allergen on the control visit and stress visit for each of the eight patients. Compared to the control visit, mean decrease in FEV1 was significantly attenuated on the stress visit. Small bar: mean. *: $\mathrm{p}<0.05$.

to re-experiencing the stressful situations. Although adrenaline levels were not measured in this study, it is likely that they were elevated in all the patients while they were reexperiencing emotional stress. This is because SP, DP and $f \mathrm{C}$ were each significantly elevated on the stress visit as compared to the control visit (fig. 2). These cardiovascular parameters are considered good indicators of enhanced sympathetic stimulation [5]. As a $\beta$-receptor agonist, adrenaline affects two key elements involved in reversing or preventing allergic asthma: bronchiolar smooth muscle relaxation and mast cell stability.

The results presented here contrast with those from several other studies [20-22]. This could be due to the types of patients that participated in each study. In the present study, females with a history of extrinsic asthma (i.e. allergicasthma) alone were included, whereas the previous studies included males who may have had either extrinsic or intrinsic asthma. Another explanation could be due to differences in the type of emotion that was elicited in each of the studies. In the case of CLARKE [21] and SMITH et al. [22], fear and anger were elicited. In the current study, sadness was usually expressed.

Another explanation could be that verbally re-experiencing a stressful situation is protective under certain circumstances. Several investigators have recently measured the effects of re-experiencing a stressor or negative life event, verbally or through writing, on asthma symptoms [23] or on the immune response in general [24, 25]. SMYTH et al. [23] found that asthma patients who were randomly assigned to write about a stressful experience improved their FEV1 from $63.9 \%$ at baseline to $76.3 \% 4$ months after the intervention, whereas patients who were assigned to write about a neutral experience showed no change. EsTERLING et al. [25] found that healthy Epstein-Barr virus (EBV) seropositive undergraduates who were assigned to verbally disclose stressful events on a number of occasions had significantly lower EBV titres in the blood after the verbal disclosures than students who were assigned to only write about stressful events.

LIU et al. [8] recently published findings based on an allergen challenge paradigm that was similar to the one in the current study. However, that study was designed to answer a different question about the role of stress in exacerbating asthma. LIU et al. [8] set up their protocol to determine if a relatively chronic stressful life event, such as the stress associated with final examinations, increases airway inflammation that occurs 6-24 $\mathrm{h}$ after the inhalation of antigen in patients with allergic asthma. The present study was designed to determine if an acute stressor, such as re-experiencing an intense psychological event, increases the airway constriction that occurs immediately after allergen inhalation (early pulmonary response) in the same population. LIU et al. [8] found that the chronic stressor significantly increased eosinophilic airway inflammation after the challenge. It was found here that re-experiencing the acute stressor slightly attenuated the early pulmonary response to inhaled allergen. The current authors did not measure indices of airway inflammation in this study. LiU et al. [8] did not measure cardiovascular parameters in theirs. The findings from these two studies suggest that the effects of acute stress on airway functioning may be largely mediated through the autonomic nervous system, whereas chronic stress may lead to alterations in the immune system.

The current findings are preliminary in nature and only pertain to the effect of verbally re-experiencing an emotional stressor on the immediate pulmonary response to allergen exposure.

\begin{abstract}
Acknowledgements. The authors would like to thank G. Weinmann and C. Mitchell for providing medical back-up, and Johnson \& Johnson, Inc. for providing the Dinamap 8100 automated blood pressure monitor.
\end{abstract}

\section{References}

1. Cohen S, Kessler RC, Underwood-Gordon L. Strategies for measuring stress in studies of psychiatric and physical disorders. In: Measuring Stress. Cohen S, Kessler RC, Underwood-Gordon L, eds. New York, Oxford University Press, 1995; pp. 3-28.

2. Busse WW, Kiecolt-Glaser JK, Coe C, Martin RJ, Weiss ST, Parker SR. Stress and asthma. Am J Respir Crit Carce Med 1995; 151: 249-252.

3. Fritz GK. Psychological issues in assessing and managing asthma in children. Clin Rev Allergy 1987; 5: 259-227.

4. Huckauf H, Macha N. Behavioral factors in the etiology of asthma. Chest 1987; 6: 141S-143S.

5. Rietveld S, Van Beest I, Everaerd W. Stress-induced breathlessness in asthma. Psychological Med 1999; 29: 1359-1366.

6. Ritz T, Steptoe A, DeWilde S, Costa M. Emotions and stress increase respiratory resistance in asthma. Psychosomatic Med 2000; 62: 401-412.

7. McQuaid EL, Fritz GK, Nassau JH, Lilly MK, Mansell A, Klein RB. Stress and airway resistance in children with asthma. J Psychosomatic Res 2000; 49: 239-245.

8. Liu LY, Coe CL, Swenson CA, Kelly EA, Kita H, Busse WW. School examinations enhance airway inflammation to antigen challenge. Am J Respir Crit Care Med 2002; 165: $1062-1067$.

9. Conger RD, Lorenz FO, Elder GH, Simons RL, Ge X. Husband and wife differences in response to undesirable life events. J Health Soc Behavior 1993; 34: 71-88.

10. Allen MT. Stoney CM, Owens JF, Matthews KA. Hemodynamic adjustments to laboratory stress: the influence of gender and personality. Psychosomatic Med 1993; 55: 505-517.

11. Burns JW, Katkin ES. Psychological, situational, and gender predictors of cardiovascular reactivity to stress: a multivariate approach. J Behavioral Med 1993; 16: 445-465.

12. Engebretson TO, Matthews KA. Dimensions of hostility in men, women and boys: relationships to personality and cardiovascular responses to stress. Psychosomatic Med 1992; 54: 311-323

13. Dodge RR, Burrows B. The prevalence and incidence of 
asthma-like symptoms in a general population sample Am Rev Respir Dis 1980; 122: 567-575.

14. Skobeloff EM, Spivey WH, St. Vlair SS, Schoffstall JM. The influence of age and sex on asthma admissions. JAMA 1992; 268: $3437-3440$.

15. Chai H, Farr RS, Froehlich LA, et al. Standardization of bronchial inhalation challenge procedures. J Allergy Clin Immunol 1975; 56: 323-327.

16. Pretty GMH, McCarthy ME, Catano VM. Psychological environments and burnout: gender considerations within the corporation. J Organizational Behavior 1992; 13: 701-711.

17. Moos RH. Development and applications of new measures of life stressors, social resources and coping responses. Eur J Psych Assess 1995; 11: 1-13.

18. Laube BL, Swift DL, Adams GK III. Single-breath deposition of jet-nebulized saline aerosol. Aerosol Sci Tech 1984; 3: 97-102.

19. Ewart CK, Kolodner KB. Social competence interview for assessing physiological reactivity in adolescents. Psychosomatic Med 1991; 53: 289-304.
20. Tal A, Miklich DR. Emotionally induced decreases in pulmonary flow rates in asthmatic children. Psychosomatic Med 1976; 38: 190-200.

21. Clarke PS. Effects of emotion and cough on airways obstruction in asthma. Med J Australia 1970; 1: 535-537.

22. Smith MS, Colebach HJ, Clarke PS. Increase and decrease in pulmonary resistance with hypnotic suggestion in asthma. Am Rev Respir Dis 1970; 102: 236-242.

23. Smyth JM, Stone AA, Hurewitz A, Kaell A. Effects of writing about stressful experiences on symptom reduction in patients with asthma or rheumatoid arthritis. A randomized trial. JAMA 1999; 281: 1304-1309.

24. Petrie KJ, Booth RJ, Pennebaker JW, Davison KP, Thomas MG. Disclosure of trauma and immune response to a hepatitis B vaccination program. $J$ Consulting Clin Psychology 1995; 63: 787-792.

25. Esterling BA, Antoni $\mathrm{MH}$, Fletcher MA, Margulies S, Schneiderman N. Emotional disclosure through writing or speaking modulates latent Epstein-Barr virus antibody titers. J Consulting Clin Psychology 1994; 62: 130-140. 